\title{
GMR
}

\section{Leptin (rs 7799039) and solute carrier family 30 zinc transporter (rs13266634) polymorphisms in Euro-Brazilian pregnant women with gestational diabetes}

\author{
A. Teleginski ${ }^{1}$, M. Welter ${ }^{1}$, H.R. Frigeri ${ }^{1,2}$, R.R. Réa ${ }^{3}$, E.M. Souza ${ }^{4}$, \\ D. Alberton ${ }^{1}$, F.G.M. Rego ${ }^{1}$ and G. Picheth ${ }^{1}$ \\ ${ }^{1}$ Programa de Pós-Graduação em Ciências Farmacêuticas, \\ Universidade Federal do Paraná, Curitiba, PR, Brasil \\ ${ }^{2}$ Escola de Ciências da Vida, Pontifícia Universidade Católica do Paraná, \\ Curitiba, PR, Brasil \\ ${ }^{3}$ Serviço de Endocrinologia e Metabologia do Paraná, Hospital de Clínicas, \\ Curitiba, PR, Brasil \\ ${ }^{4}$ Departamento de Bioquímica e Biologia Molecular, \\ Universidade Federal do Paraná, Curitiba, PR, Brasil \\ Corresponding author: G. Picheth \\ E-mail: geraldopicheth@gmail.com / gpicheth@ufpr.br
}

Genet. Mol. Res. 16 (1): gmr16019515

Received November 3, 2016

Accepted January 30, 2017

Published March 30, 2017

DOI http://dx.doi.org/10.4238/gmr16019515

Copyright $(2017$ The Authors. This is an open-access article distributed under the terms of the Creative Commons Attribution ShareAlike (CC BY-SA) 4.0 License.

ABSTRACT. Leptin (LEP), a protein that plays a fundamental role
in the metabolism of energy reserves, and the solute carrier family
30 A8 zinc transporter (SLC30A8) have been consistently associated
with diabetes. Women with gestational diabetes are at moderate risk
of developing diabetes type 1 and 2 after pregnancy, in addition
to complications to the fetus. We investigated the association of the
polymorphisms rs 7799039 (LEP) and rs 13266634 (SLC30A8) in a
case-control study in Euro-Brazilians with gestational diabetes (GDM,

Genetics and Molecular Research 16 (1): gmr16019515 
$\mathrm{N}=134$ ) and healthy pregnant women (control, $\mathrm{N}=180$ ). Realtime PCR with fluorescent probes (TaqMan system) was applied to genotyping. All polymorphisms were in Hardy-Weinberg equilibrium. The minor allele frequencies, for healthy and GDM, respectively, for the A-allele (LEP gene $r s 7799039)$ were $40.3 \%(95 \% \mathrm{CI}=35-45 \%)$ vs $36.6 \%(95 \% \mathrm{CI}=31-42 \%), \mathrm{P}=0.345$; and for the T-allele (SLC30A8 gene $r s 13266634)$ were $27.8 \%(95 \% \mathrm{CI}=23-32 \%)$ vs $23.5 \%(95 \% \mathrm{CI}$ $=18-29 \%), \mathrm{P}=0.227$. Genotype comparisons for both polymorphisms showed no significant difference $(\mathrm{P}>0.05)$. The polymorphisms rs7799039 and rs13266634 were not associated with GDM in the population studied $(\mathrm{P}>0.05)$. The minor allele frequencies for both polymorphisms were similar to those of other Caucasian populations.

Key words: Gestational diabetes; Leptin; Genetic susceptibility; SNP; Solute carrier family 30 (zinc transporter) member 8; Mutation

\section{INTRODUCTION}

The number of adults with diabetes worldwide increased from 108 million in 1980 to about 422 million by the year 2014 [NCD Risk Factor Collaboration (NCD-RisC), 2016], and this number is estimated to increase to 592 million by 2035 (IDF - International Diabetes Federation, 2014).

Diabetes mellitus is a group of metabolic diseases that has a defect in insulin secretion, insulin action, or both, resulting in chronic hyperglycemia. Women with a history of gestational diabetes mellitus (GDM) are at increased risk of developing type 2 diabetes mellitus (T2D) compared to those whose pregnancy is normoglycemic (Kwak et al., 2013).

Glucose metabolism and insulin sensitivity always change in pregnant women who are usually able to meet the increased insulin demand, but in some cases, these requirements are not met, resulting in poor glycemic control (Liu et al., 2016).

GDM is usually diagnosed in the last half of pregnancy when insulin resistance increases progressively until birth. Risk factors for this disorder include obesity, advanced maternal age, and a family history of diabetes. Although GDM occurs frequently, its pathophysiology is not completely understood. Little is known about the gene expression profile in GDM. However, GDM is a common metabolic disorder affecting $1-14 \%$ of all pregnancies, and each year, the incidence of cases increases (Singh and Singh, 2015).

One of the most frequent types of genetic variation in the human genome is the single nucleotide polymorphism (SNP), which may contribute to differences between individuals in susceptibility to hereditary diseases. Polymorphisms in different genes have been associated with GDM (Huopio et al., 2013).

The LEP gene (Leptin, OMIM: 164160) is located on chromosome 7, in area 7q31.3, is 16,352 bp in length, and contains 3 exons. Leptin is a hormone secreted by adipocytes that promote a reduction in fuel uptake and an increase in energy expenditure when fat reserves are sufficient, thus controlling body weight and regulating energy balance (Jéquier and Tappy, 1999). Reduction in the leptin level reverses the process of thermogenesis, allowing fuel conservation (Jéquier and Tappy, 1999).

In addition to regulating appetite and metabolism, this adipokine is important in insulin

Genetics and Molecular Research 16 (1): gmr16019515 
secretion (Romanowski et al., 2015). Insulin resistance is an important feature of gestational diabetes mellitus. Several adipokines, including leptin, are involved in the development of this resistance (Takhshid and Zare, 2015).

The hormone leptin was first identified in adipose tissue and is known to be expressed in the placenta and fetal tissues (Vaskú et al., 2006). Leptin is considered a fetal growth factor able to maintain energy and metabolic balance during pregnancy (Xu et al., 2014). Polymorphisms in the leptin gene have been associated with obesity, a risk factor for GDM and T2D. The polymorphism rs7799039 is located in the promoter region of the LEP gene and can alter dynamic methylation, affecting LEP expression at the transcriptional level to increase or reduce leptin expression (Marcello et al., 2015).

The SLC30A8 gene (Solute Carrier Family 30 zinc transporter, OMIM 611145) is 226,442 bp in length and is located in the region 8q24.11 of chromosome 8 (Seman et al., 2015).

SLC30A8 is associated with the secretion of human insulin and encodes a specific zinc transporter (ZnT8) for $\beta$ cells of the pancreas (Maruthur et al., 2015). The presence of zinc in the secretory insulin vesicles stabilizes the insulin hexamer, making it less susceptible to degradation (Dereke et al., 2016). This insulin packed into secretory vesicles becomes available for immediate release upon stimulation by glucose (Maruthur et al., 2015). The polymorphism $r s 13266634$ is a non-synonymous $\mathrm{C} \rightarrow$ T mutation in exon 9 of the SLC30A8 gene, causing a non-conservative change of arginine (R) to tryptophan (W) at position 325 (R325W) (Dereke et al., 2016).

The polymorphisms rs7799039 and rs 13266634 affecting the expression of the LEP and SLC30A8 genes, respectively, have been considered likely to be associated with diabetes risk. Insufficient production of leptin is usually related to human obesity and with altered glucose metabolism. The negative regulation of the zinc transporter is thought to destabilize insulin molecules (Seman et al., 2015).

The aim of this study was to determine if the polymorphisms rs7799039 and rs 13266634 were associated with gestational diabetes in a case-control study with healthy and diabetic Euro-Brazilian pregnant women.

\section{MATERIAL AND METHODS}

\section{Study subjects}

A sample of 314 unrelated Euro-Brazilian pregnant women was classified as healthy (control, $\mathrm{N}=180$ ) or with gestational diabetes (GDM, $\mathrm{N}=134$ ) according to the Brazilian Diabetes Society (SBD, 2009). Briefly, GDM diagnosis was defined at 24-28 weeks of gestation by fasting glucose $\geq 6.1 \mathrm{mmol} / \mathrm{L}$, and by a glucose level $>7.8 \mathrm{mmol} / \mathrm{L}, 2-\mathrm{h}$ after an oral glucose load of $75 \mathrm{~g}$.

Clinical and anthropometric data were obtained from all patients. The study was approved by the University's Human Research Ethics Committee.

\section{DNA extraction}

Genomic DNA was obtained from peripheral blood leukocytes (buffy coat) by the salting-out method (Lahiri and Nurnberger, 1991). DNA samples with an $\mathrm{A}_{260} / \mathrm{A}_{280}$ ratio between 1.6 and 1.9 were used, and the concentrations of all samples were normalized to $20 \mathrm{ng} / \mu \mathrm{L}$.

Genetics and Molecular Research 16 (1): gmr16019515 
TaqMan SNP Genotyping Assays ${ }^{\circledR}$ (Applied Biosystems, Foster City, CA, USA) utilizing fluorescent probes in the 7500 Fast Real-Time PCR System (Applied Biosystems) were used for genotyping. The TaqMan probe codes used were C_1328079_10 (rs7799039; LEP) and C_3578888_10 (rs 13266634, SLC30A8). Briefly, the genotyping protocol involved the addition of $3 \mu \mathrm{L}$ DNA $(20 \mathrm{ng} / \mu \mathrm{L}), 3 \mu \mathrm{L}$ TaqMan Genotyping Master Mix, $0.1 \mu \mathrm{L}$ of each fluorescent probe and $1.9 \mu \mathrm{L}$ water to each well of a 96-well plate. The cycling protocol was as recommended by the manufacturer $\left(1\right.$ cycle: $95^{\circ} \mathrm{C}$ for $10 \mathrm{~min}$, and 40 cycles: $95^{\circ} \mathrm{C}$ for $15 \mathrm{~s}$ and $60^{\circ} \mathrm{C}$ for $60 \mathrm{~s}$ ). The Genotyping quality was $98 \%$ or higher in all samples measured by the software (7500 Fast SDS system software).

\section{Biochemical markers}

Biochemical parameters such as fasting glucose, glucose $2 \mathrm{~h}$ after $75 \mathrm{~g}$ oral glucose load, creatinine, and albumin were quantified using the Architect Ci 8200 automated system (Abbott Diagnostics) with reagents, calibrators, and controls from the equipment manufacturer. Glycated hemoglobin (HbAlc) was measured only in diabetic pregnant women by using a high-performance liquid chromatography (HPLC) machine equipped with a cation exchange column (Varian II, Bio-Rad).

\section{Statistical analysis}

Continuous variables with normal distribution, verified with Kolmogorov-Smirnov test, were compared with a two-tailed Student $t$-test for independent variables. The MannWhitney U-test was used for non-normal distribution variables. The chi-square test was used to compare categorical variables. Hardy-Weinberg equilibrium and allele comparisons were calculated with the DeFinetti program (http://ihg.gsf.de/cgi-bin/hw/hwa1.pl).

Statistical analyses were performed using the Statistica for Windows version 8.0 software (StatSoft Inc., Tulsa, OK, USA). A P value lower than 5\% $(\mathrm{P}<0.05)$ was considered significant.

\section{RESULTS}

Patient characteristics are shown in Table 1. GDM patients were older (median age 32 vs 30 years) and heavier (BMI 32.6 s $26.1 \mathrm{~kg} / \mathrm{m}^{2}$ ) compared with healthy pregnant controls. A history of family diabetes was high in the GDM group (66.7\%) when compared to other Euro-descendent healthy pregnant women from Portugal (16\%) (Ribeiro et al., 2015) and France (16\%) (Miailhe et al., 2015). This information for the control group was not available.

Table 1. Anthropometric and laboratory data for healthy women and women with GDM.
\begin{tabular}{|l|c|c|c}
\hline Parameters & Control $(\mathrm{N}=180)$ & GDM $(\mathrm{N}=134)$ & P \\
\hline Age (years) & $30(28-33)$ & $32(28-36)$ & $0.034^{*}$ \\
\hline Weight $(\mathrm{kg})$ & $66(58-73)$ & $82(71-93)$ & $<0.001^{*}$ \\
\hline Height $(\mathrm{m})$ & $1.61 \pm 0.06$ & $1.60 \pm 0.06$ & 0.109 \\
\hline BMI $\left(\mathrm{kg} / \mathrm{m}^{2}\right)$ & $26.1 \pm 5.1$ & $32.6 \pm 6.4$ & $<0.001$ \\
\hline Family history of Diabetes $(\%)$ & - & 66.7 & - \\
\hline Fasting glucose $(\mathrm{mM})$ & $4.6(4.4-4.9)$ & $4.8(4.0-5.4)$ & $<0.001^{*}$ \\
\hline Glucose $2-\mathrm{h}, 75 \mathrm{~g}(\mathrm{mM})$ & $4.8(4.4-5.7)$ & $9.0(8.3-9.7)$ & $<0.001^{*}$ \\
\hline HbA1c $(\%)$ & - & $5.8(5.2-6.0)$ & - \\
\hline Creatinine $(\mu \mathrm{M})$ & $70.7(70.3-79.6)$ & $61.9(53.0-70.7)$ & $<0.001^{*}$ \\
\hline Albumin $(\mathrm{g} / \mathrm{L})$ & $43.0(39-46)$ & $34.0(31-36)$ & $<0.001^{*}$ \\
\hline
\end{tabular}

Genetics and Molecular Research 16 (1): gmr16019515 
Control, healthy pregnant women and GDM, women with gestational diabetes mellitus. Values are reported as means $\pm \mathrm{SD}$, median (interquartile range) or \%. -, no information available. P value, Student $t$-test independent (two-sided), *Mann-Whitney U test.

Fasting glucose, and the glucose level $2 \mathrm{~h}$ after a 75 -g glucose load, were high in the GDM group as expected $(\mathrm{P}<0.001)$. Glycated hemoglobin, measured only in the GDM group (median 5.8\%), suggested good glycemic control, and none of these patients were receiving insulin therapy. Serum creatinine and albumin were lower in the GDM than in the control group, but both markers were in the reference range.

Genotypes and allele frequencies of both polymorphisms showed no differences between the studied groups (Table 2). The polymorphisms were in Hardy-Weinberg equilibrium $(\mathrm{P}>0.05)$ in both groups. For both polymorphisms, the genotype comparison in the modules dominant (frequent homozygous $v s$ others) and recessive (rare homozygous $v s$ others) did not show significance $(\mathrm{P}>0.05)$.

\begin{tabular}{|c|c|c|c|c|}
\hline \multirow{5}{*}{$\begin{array}{l}\text { Gene//Polymorphisms } \\
L E P, \text { rs7799039 }\end{array}$} & & Control $(\mathrm{N}=180)$ & GDM $(\mathrm{N}=134)$ & $\mathrm{P}$ \\
\hline & & & & 0.627 \\
\hline & $\mathrm{G} / \mathrm{G}$ & $67(37.2 \%)$ & $57(42.5 \%)$ & \\
\hline & $\mathrm{G} / \mathrm{A}$ & $81(45.0 \%)$ & $56(41.8 \%)$ & \\
\hline & $\mathrm{A} / \mathrm{A}$ & $32(17.8 \%)$ & $21(15.7 \%)$ & \\
\hline \multirow{5}{*}{$\begin{array}{l}\text { MAF } \\
S L C 30 A 8, \text { rs } 13266634\end{array}$} & A-allele $(95 \% \mathrm{CI})$ & $40.3 \%(35-45 \%)$ & $36.6 \%(31-42 \%)$ & $0.345^{*}$ \\
\hline & & & & 0.522 \\
\hline & $\mathrm{C} / \mathrm{C}$ & $99(55.1 \%)$ & $82(61.2 \%)$ & \\
\hline & $\mathrm{C} / \mathrm{T}$ & $62(34.4 \%)$ & $41(30.6 \%)$ & \\
\hline & $\mathrm{T} / \mathrm{T}$ & $19(10.5 \%)$ & $11(8.2 \%)$ & \\
\hline MAF & T-allele $(95 \% \mathrm{CI})$ & $27.8 \%(23-32 \%)$ & $23.5 \%(18-29 \%)$ & $0.227^{*}$ \\
\hline
\end{tabular}

MAF, minor allele frequency. All polymorphisms were in Hardy-Weinberg equilibrium. P value, chi-squared test for genotype and *allele frequencies $95 \% \mathrm{CI}=95 \%$ confidence interval.

For Euro-Brazilian healthy pregnant women, the minor allele frequency for $r s 7799039$ (A-allele; LEP gene) was $40.3 \%(95 \% \mathrm{CI}=35-45 \%)$ and for $r s 13266634$ (T-allele; SLC30A8 gene) $27.8 \%(95 \% \mathrm{CI}=23-32 \%)$.

\section{DISCUSSION}

The number of cases of gestational diabetes mellitus in Brazil reaches $7 \%$ of pregnancies, similar to the rate in the United States (Schmidt et al., 2000). The prevalence varies in different populations and ethnic groups (Zhang et al., 2013).

In this study, diabetic pregnant women were older than healthy controls. Increasing age is known to correlate with the risk of developing GDM. In the sample analyzed, the median age for diabetic pregnant women was 32 years, in accordance with the literature, where there are reports that the prevalence of gestational diabetes increases with age, becoming more frequent in women from the age of 30 onward (Murgia et al., 2008).

Regarding weight and BMI, the group of diabetic women had significantly higher values than the control group. This was as expected given that being overweight and having obesity (BMI $>30 \mathrm{~kg} / \mathrm{m}^{2}$ ) are factors that contribute to the development of GDM (Murgia et al., 2008; Takhshid and Zare, 2015). 
A family history of diabetes also influences the development of GDM. Almost $67 \%$ of gestational diabetic patients in the study reported a family history of diabetes. In a study by Murgia et al. (2008), women with GDM also reported having first-degree relatives with diabetes, confirming that GDM and T2D have similar genetic character. Mothers with gestational diabetes have a higher incidence of T2D development, while their children are at greater risk of developing obesity (Huidobro et al., 2010).

The glycated hemoglobin is a biomarker of glycemic control (Arnold and Wang, 2014). Concentrations greater than $6.5 \%$ indicate inadequate glycemic control (SBD, 2009). Average concentrations of HbA1c for the GDM group of 5.8\% suggest good glycemic control in these patients (Table 1).

The BMI, age, and $\mathrm{HbA} 1 \mathrm{c}$ parameters of pregnant women in the groups in question were similar to those in pregnant women in groups of similar studies (Huopio et al., 2013; Takhshid and Zare, 2015).

There were significant differences in mean serum albumin and creatinine concentrations between the two groups. The GDM group showed lower concentrations of both markers compared to concentrations in the control group (Table 1). This reduction may be explained by increased protein loss in these patients and increased urine flow resulting from hyperglycemia, suggesting a reason for the decreased serum creatinine. Nevertheless, none of these biomarkers point to overt kidney failure or hypertension problems since they were in the reference range (Lim, 2014).

Leptin gene polymorphisms are associated with obesity, insulin resistance, and diabetes mellitus, as demonstrated in a study by (Romanowski et al., 2015). The association of polymorphisms in the leptin gene with GDM is controversial. Vaskú et al. (2006) showed an association of leptin polymorphism -2548G $>$ A with preeclampsia in GDM, but Yang et al. (2016) failed to associate this polymorphism with GDM in a Chinese population.

The minor allele frequency (MAF) of the LEP gene polymorphism rs 7799039 (A-allele) for the control group $(\sim 40 \%)$ was similar to the frequency in Bulgaria (45\%), Egypt (39.5\%), and India (41.1\%), as shown in Table 3. Caucasians from Finland and Germany showed slightly higher frequencies (50-58\%). Different African populations showed dramatically different frequencies, such as $4 \%$ in one African study compared with $98.7 \%$ for Nigerians. A different Euro-Brazilian population, studied by Luperini et al. (2015), showed a frequency (41.1\%) consistent with that observed in our study.

Studies using diabetic mice have shown that the gene expression level of SLC30A8 is repressed in the pancreas of animals that present this pathology, suggesting an involvement in diabetes (Seman et al., 2015).

The MAF of the SLC30A8 gene rs 13266634 (T-allele) for the control group $(\sim 28 \%)$ was similar to that found in Indian $(23 \%)$, Mayan $(25 \%)$, American $(26.2 \%)$, and Polish (33\%) populations. Orientals showed a higher frequency $(\sim 46 \%)$ and Africans a lower frequency $(6-8 \%)$ as presented in Table 3. No studies were found for Brazilian populations.

Our findings should be confirmed with a larger sample size.

In summary, the studied polymorphisms (rs7799039; LEP and rs 13266634; SLC30A8) were not associated with gestational diabetes in a Euro-Brazilian population.

Genetics and Molecular Research 16 (1): gmr16019515 
Table 3. Comparison of minor allele frequencies of rs7799039 and rs13266634 with other populations.

\begin{tabular}{l|c|l}
\hline Ethnic group & MAF $(\%)(95 \% \mathrm{CI})$ & References \\
\hline Euro-Brazilian & LEP/rs7799039 (A-allele) & This work \\
\hline Nigerian (Yoruban) & $\mathbf{4 0 . 3 ( 3 5 - 4 5 )}$ & HapMap \\
\hline Caucasian (Germany) & $\mathbf{9 8 . 7}$ & (Opgen-Rhein et al., 2010 \\
\hline Indian Obese & $\mathbf{5 8 . 3 ( 5 0 - 6 7 )}$ & (Dasgupta et al., 2015) \\
\hline Caucasian (Finland) & $\mathbf{5 3 . 9}$ & (Dougkas et al., 2013) \\
\hline Bulgarian & $\mathbf{5 0 . 0}$ & (Nikolova et al., 2015) \\
\hline Indian Lean & 45.0 & (Dasgupta et al., 2015) \\
\hline Euro-Brazilian & 43.2 & (Luperini et al., 2015) \\
\hline Egyptian & 41.1 & (Mehanna et al., 2016) \\
\hline Asian (China) & 39.5 & (Wu et al., 2011) \\
\hline African & $\mathbf{3 0 . 0}(\mathbf{2 3 - 3 7})$ & (Okpechi et al., 2010) \\
\hline & $\mathbf{4 . 0}$ & \\
\hline Euro-Brazilian & $\mathbf{2 7 . 8 ( 2 3 - 3 2 )}$ & This work \\
\hline East Asian & $\mathbf{4 6 . 0}$ & (Lara-Riegos et al., 2015) \\
\hline Han Chinese & $\mathbf{4 5 . 5}$ & (Zhang et al., 2015) \\
\hline Asian (China) & $\mathbf{4 3 . 4 ( 3 8 - 4 9 )}$ & (Zheng et al., 2012) \\
\hline Caucasian (Poland) & $33.0(28-38)$ & (Kurzawski et al., 2012) \\
\hline European & 28.6 & (Lara-Riegos et al., 2015) \\
\hline American & 26.2 & (Lara-Riegos et al., 2015) \\
\hline Mayan & 25.0 & (Lara-Riegos et al., 2015) \\
\hline Indian & 23.0 & (Khan et al., 2015) \\
\hline African & $\mathbf{8 . 3}$ & (Lara-Riegos et al., 2015) \\
\hline Nigerian (Yoruban) & $\mathbf{6 . 1}$ & HapMap \\
\hline
\end{tabular}

$\mathrm{MAF}=$ minor allele frequency $(\%) ; 95 \% \mathrm{CI}=$ confidence interval. HapMap (http://www.hapmap.org/). In bold: MAF outside the $95 \% \mathrm{CI}$ obtained in our study.

\section{Conflicts of interest}

The authors declare no conflict of interest.

\section{ACKNOWLEDGMENTS}

Research supported by CNPq - Conselho Nacional de Desenvolvimento Científico e Tecnológico and Araucária Foundation.

\section{REFERENCES}

Arnold LW and Wang Z (2014). The HbA1c and all-cause mortality relationship in patients with type 2 diabetes is J-shaped: a meta-analysis of observational studies. Rev. Diabet. Stud. 11: 138-152. http://dx.doi.org/10.1900/RDS.2014.11.138

Dasgupta S, Salman M, Siddalingaiah LB, Lakshmi GL, et al. (2015). Genetic variants in leptin: Determinants of obesity and leptin levels in South Indian population. Adipocyte 4: 135-140. http://dx.doi.org/10.4161/21623945.2014.975538

Dereke J, Palmqvist S, Nilsson C, Landin-Olsson M, et al. (2016). The prevalence and predictive value of the SLC30A8 R325W polymorphism and zinc transporter 8 autoantibodies in the development of GDM and postpartum type 1 diabetes. Endocrine 53: 740-746. http://dx.doi.org/10.1007/s12020-016-0932-7

Dougkas A, Yaqoob P, Givens DI, Reynolds CK, et al. (2013). The impact of obesity-related SNP on appetite and energy intake. Br. J. Nutr. 110: 1151-1156. http://dx.doi.org/10.1017/S0007114513000147

Huidobro A, Prentice A, Fulford T, Parodi C, et al. (2010). Gestational diabetes, comparison of women diagnosed in second and third trimester of pregnancy with non GDM women: Analysis of a cohort study. Rev. Med. Chil. 138: 316-321. http://dx.doi.org/10.4067/S0034-98872010000300009

Huopio H, Cederberg H, Vangipurapu J, Hakkarainen H, et al. (2013). Association of risk variants for type 2 diabetes and hyperglycemia with gestational diabetes. Eur. J. Endocrinol. 169: 291-297. http://dx.doi.org/10.1530/EJE-13-0286

IDF - International Diabetes Federation (2014). Diabetes Atlas - 2014 update - Sixth edition, Regional fact sheets, Data for the seven regions of IDF. Available at [http://www.idf.org/sites/default/files/DA-regional-factsheets-2014_FINAL.pdf].

Genetics and Molecular Research 16 (1): gmr16019515 
Jéquier E and Tappy L (1999). Regulation of body weight in humans. Physiol. Rev. 79: 451-480.

Khan IA, Poornima S, Jahan P, Rao P, et al. (2015). Type 2 Diabetes Mellitus and the Association of Candidate Genes in Asian Indian Population from Hyderabad, India. J. Clin. Diagn. Res. 9: GC01-GC05.

Kurzawski M, Dziewanowski K, Łapczuk J, Wajda A, et al. (2012). Analysis of common type 2 diabetes mellitus genetic risk factors in new-onset diabetes after transplantation in kidney transplant patients medicated with tacrolimus. Eur. J. Clin. Pharmacol. 68: 1587-1594. http://dx.doi.org/10.1007/s00228-012-1292-8

Kwak SH, Choi SH, Jung HS, Cho YM, et al. (2013). Clinical and genetic risk factors for type 2 diabetes at early or late post partum after gestational diabetes mellitus. J. Clin. Endocrinol. Metab. 98: E744-E752. http://dx.doi.org/10.1210/ ic. $2012-3324$

Lahiri DK and Nurnberger JI, Jr. (1991). A rapid non-enzymatic method for the preparation of HMW DNA from blood for RFLP studies. Nucleic Acids Res. 19: 5444. http://dx.doi.org/10.1093/nar/19.19.5444

Lara-Riegos JC, Ortiz-López MG, Peña-Espinoza BI, Montúfar-Robles I, et al. (2015). Diabetes susceptibility in Mayas: Evidence for the involvement of polymorphisms in HHEX, HNF4 $\alpha$, KCNJ11, PPAR $\gamma, \mathrm{CDKN} 2 \mathrm{~A} / 2 \mathrm{~B}, \mathrm{SLC} 30 \mathrm{~A} 8$, CDC123/CAMK1D, TCF7L2, ABCA1 and SLC16A11 genes. Gene 565: 68-75. http://dx.doi.org/10.1016/j. gene.2015.03.065

Lim AKh (2014). Diabetic nephropathy - complications and treatment. Int. J. Nephrol. Renovasc. Dis. 7: 361-381. http:// dx.doi.org/10.2147/IJNRD.S40172

Liu Q, Huang Z, Li H, Bai J, et al. (2016). Relationship between melatonin receptor 1B (rs10830963 and rs1387153) with gestational diabetes mellitus: a case-control study and meta-analysis. Arch. Gynecol. Obstet. 294: 55-61. http:// dx.doi.org/10.1007/s00404-015-3948-y

Luperini BC, Almeida DC, Porto MP, Marcondes JP, et al. (2015). Gene polymorphisms and increased DNA damage in morbidly obese women. Mutat. Res. 776: 111-117. http://dx.doi.org/10.1016/j.mrfmmm.2015.01.004

Marcello MA, Calixto AR, de Almeida JF, Martins MB, et al. (2015). Polymorphism in LEP and LEPR May Modify Leptin Levels and Represent Risk Factors for Thyroid Cancer. Int. J. Endocrinol. 2015: 173218. http://dx.doi. org/10.1155/2015/173218

Maruthur NM, Clark JM, Fu M, Linda Kao WH, et al. (2015). Effect of zinc supplementation on insulin secretion: interaction between zinc and SLC30A8 genotype in Old Order Amish. Diabetologia 58: 295-303. http://dx.doi. org/10.1007/s00125-014-3419-1

Mehanna ET, Mesbah NM, Ghattas MH, Saleh SM, et al. (2016). Association of chemerin Rs17173608 and vaspin Rs2236242 gene polymorphisms with metabolic syndrome in Egyptian women. Endocr. Res. 41: 43-48. http://dx.doi. org $/ 10.3109 / 07435800.2015 .1066802$

Miailhe G, Kayem G, Girard G, Legardeur H, et al. (2015). Selective rather than universal screening for gestational diabetes mellitus? Eur. J. Obstet. Gynecol. Reprod. Biol. 191: 95-100. http://dx.doi.org/10.1016/j.ejogrb.2015.05.003

Murgia C, Berria R, Minerba L, Sulis S, et al. (2008). Risk assessment does not explain high prevalence of gestational diabetes mellitus in a large group of Sardinian women. Reprod. Biol. Endocrinol. 6: 26. http://dx.doi.org/10.1186/1477-7827-6-26

NCD Risk Factor Collaboration (NCD-RisC) (2016). Worldwide trends in diabetes since 1980: a pooled analysis of 751 population-based studies with 4.4 million participants. Lancet 387: 1513-1530. http://dx.doi.org/10.1016/S01406736(16)00618-8

Nikolova S, Dikova M, Dikov D, Djerov A, et al. (2015). Role of the IL-6 gene in the etiopathogenesis of idiopathic scoliosis. Anal. Cell Pathol. (Amst.) 2015: 621893. http://dx.doi.org/10.1155/2015/621893

Okpechi IG, Rayner BL, van der Merwe L, Mayosi BM, et al. (2010). Genetic variation at selected SNPs in the leptin gene and association of alleles with markers of kidney disease in a Xhosa population of South Africa. PLoS One 5: e9086. http://dx.doi.org/10.1371/journal.pone.0009086

Opgen-Rhein C, Brandl EJ, Müller DJ, Neuhaus AH, et al. (2010). Association of HTR2C, but not LEP or INSIG2, genes with antipsychotic-induced weight gain in a German sample. Pharmacogenomics 11: 773-780. http://dx.doi. org $/ 10.2217 /$ pgs. 10.50

Ribeiro AMC, et al. (2015). Diabetes gestacional: determinação de fatores de risco para diabetes mellitus. Rev Port Endocrinol Diabetes Metab. 10: 8-13.

Romanowski M, Dziedziejko V, Maciejewska-Karlowska A, Sawczuk M, et al. (2015). Adiponectin and leptin gene polymorphisms in patients with post-transplant diabetes mellitus. Pharmacogenomics 16: 1243-1251. http://dx.doi. org/10.2217/pgs. 15.71

SBD Diretrizes da Sociedade Brasileira de Diabetes. 3. Itapevi, SP: 2009.

Schmidt MI, Matos MC, Reichelt AJ, Forti AC, et al. (2000). Prevalence of gestational diabetes mellitus--do the new WHO criteria make a difference? Brazilian Gestational Diabetes Study Group. Diabet. Med. 17: 376-380. http://dx.doi. org/10.1046/j.1464-5491.2000.00257.x

Genetics and Molecular Research 16 (1): gmr16019515 
Seman NA, Mohamud WN, Östenson CG, Brismar K, et al. (2015). Increased DNA methylation of the SLC30A8 gene promoter is associated with type 2 diabetes in a Malay population. Clin. Epigenetics 7: 30. http://dx.doi.org/10.1186/ $\underline{\text { s13148-015-0049-5 }}$

Singh AK and Singh R (2015). Metformin in gestational diabetes: An emerging contender. Indian J. Endocrinol. Metab. 19: 236-244. http://dx.doi.org/10.4103/2230-8210.149317

Takhshid MA and Zare Z (2015). Resistin - $420 \mathrm{C} / \mathrm{G}$ polymorphism and serum resistin level in Iranian patients with gestational diabetes mellitus. J. Diabetes Metab. Disord. 14: 37. http://dx.doi.org/10.1186/s40200-015-0165-y

Vaskú JA, Vaskú A, Dostálová Z and Bienert P (2006). Association of leptin genetic polymorphism -2548 G/A with gestational diabetes mellitus. Genes Nutr. 1: 117-123. http://dx.doi.org/10.1007/BF02829953

Wu R, Zhao J, Shao P, Ou J, et al. (2011). Genetic predictors of antipsychotic-induced weight gain: a case-matched multigene study. Zhong Nan Da Xue Xue Bao Yi Xue Ban 36: 720-723.

Xu X, Yang X, Liu Z, Wu K, et al. (2014). Placental leptin gene methylation and macrosomia during normal pregnancy. Mol. Med. Rep. 9: 1013-1018.

Yang M, Peng S, Li W, Wan Z, et al. (2016). Relationships between plasma leptin levels, leptin G2548A, leptin receptor Gln223Arg polymorphisms and gestational diabetes mellitus in Chinese population. Sci. Rep. 6: 23948. http://dx.doi. org/10.1038/srep23948

Zhang C, Bao W, Rong Y, Yang H, et al. (2013). Genetic variants and the risk of gestational diabetes mellitus: a systematic review. Hum. Reprod. Update 19: 376-390. http://dx.doi.org/10.1093/humupd/dmt013

Zhang Y, Xiao X, Zhang Z, Ma X, et al. (2015). Role of high-risk variants in the development of impaired glucose metabolism was modified by birth weight in Han Chinese. Diabetes Metab. Res. Rev. 31: 790-795. http://dx.doi. org/10.1002/dmrr.2670

Zheng X, Ren W, Zhang S, Liu J, et al. (2012). Association of type 2 diabetes susceptibility genes (TCF7L2, SLC30A8, PCSK1 and PCSK2) and proinsulin conversion in a Chinese population. Mol. Biol. Rep. 39: 17-23. http://dx.doi. org/10.1007/s11033-011-0705-6

Genetics and Molecular Research 16 (1): gmr16019515 